\title{
Sounding Dispersal as a Route to Empathy with the Changing Arctic
}

\author{
KAT AUSTEN
}

This article elaborates on the new media musical project The Matter of the Soul: its background, theoretical approach, methods and realization The Matter of the Soul is a musical, sculptural and performance work. It aims to engender empathy in humans with the process of dispersal and transformation in the Arctic amid the climate crisis. The work draws an analogy between human migration, the movement of water from ice to ocean in the Arctic and changing identity online.

\section{ON COMING APART}

dispersal: the action or process of distributing

or spreading things over a wide area [1]

Dispersal in the Arctic is an important process, one as appropriate for the consequences of climate change as it is for the region's rapid cultural changes. This paper explores the creation of a musical artwork, The Matter of the Soul, which connects with the process of dispersal in the Arctic. It is realized in performance and installation form and released online and on cassette.

My interest is in exploring emotional engagement and our relationship to climate change. I have related elsewhere the importance of empathy in mediating climate change in order to overcome our inability to perceive direct links of cause and consequence in a phenomenon occurring at a such a large scale [2]. In a previous work, the Coral Empathy Device [3], I developed an approach to engender empathy for a nonhuman other-coral-under anthropogenic influence. With The Matter of the Soul, I have extended this approach to the ecosystem of the Arctic, focusing on the process of dispersal, which is intrinsically linked with climate change both in terms of its physical consequences and its sociopolitical aspects.

Arctic ice is composed of fresh water; when it melts and flows into the ocean, it decreases the concentration of salt in the seawater. This has the potential to have significant impacts on ocean currents and weather systems [4]. Ice melt-

Kat Austen (artist), Christopher Ingold Laboratories, University College London, 20 Gordon Street, London, U.K. Email: iam@katausten.com.

Website: www.katausten.com. ORCID: 0000-0002-0062-1670.

See www.mitpressjournals.org/toc/lmj/29 for supplemental files associated with this issue. ing also affects the acidity of the ocean. Freshwater runoff from glaciers in the Arctic contains large amounts of organic matter-plants and soil fragments. Ocean organisms process this organic matter and in so doing release carbon dioxide into the water, increasing its acidity. The acidity of the ocean is also increased by the rising levels of atmospheric carbon dioxide, due largely to the burning of fossil fuel and a large contributor to climate change [5].

When Arctic ice melts, the water molecules that compose it begin a process of dispersal, from glaciers through streams and fjords-or directly from ice floes and icebergs-into the ocean. On their journey, they carve into the Arctic landscape valleys and gullies that are a physical expression of the process of dispersal [6]. When the water molecules move from ice to sea water, their chemical and physical environments change, which changes the way they move, vibrate and structure in relation to one another. They themselves are changed by the environment that they create.

One can draw an analogy between this process of physical dispersal and human movement between cultures, where an individual human is both a contributor to and is a receiver of the society and culture within which they exist. As a Britishborn immigrant to Germany, I bring with me aspects of British culture, which affects those with whom I have contact, and I am changed by German culture and norms. In the Arctic, visitors and migrants to the North bring with them culture from the South, which affects the culture there and vice versa.

There is a further analogy to be drawn in relation to the identity of data objects as they traverse online. Data comprises the Internet. Its meaning and value are dependent on the context through which it travels. Social media use is interwoven with the dynamic construction of identity and community by Inuit youth [7], just as it is important in framing narratives globally [8]. In the information age, these data affect climate change through human decision-making as well as through direct impact on resource consumption [9]. Music and sound data, such as that generated through this project, disperse through the Internet, changing as they travel and are reused/remixed by others.

The Matter of the Soul addresses dispersal based on the 
framework of an individual element and its emergent metastructure across these three dimensions: the water molecule and its metastructures of ice and sea water, the human individual and culture, and the data-object and the Internet. The Matter of the Soul explores the changes that occur to the individual and the metastructure through the process of dispersal: melting; migration and movement; releasing and remixing. Inherent in the process of dispersal is an ambiguity about agency and about the tension between preservation against loss and the impossibility of stasis: that is, the inevitability of change.

\section{CAPTURING SOUNDS OF DISPERSAL}

The research for The Matter of the Soul was begun during my Artist in the Arctic residency with Friends of Scott Polar Research Institute [10], One Ocean Expeditions and Bonhams in 2017. As part of the residency I sailed through the Canadian High Arctic in July and August (Fig. 1). In preparation, I visited the collections of the SPRI's Polar Museum in Cambridge, U.K., and spoke to researchers in order to explore the aesthetics of this part of the North and to elaborate my concept in terms of changes to the waters and culture in the Canadian High Arctic.

\section{Individuals | Culture}

I researched Arctic cultural histories using the Pan-Inuit Trails Atlas [11], codeveloped by SPRI anthropologist Michael Bravo. The maps show how Arctic travel changes with the season: When the ocean turns to ice it becomes differently traversable; routes and paths exist only during certain times of the year.

The term dispersal, as historically used in academic literature to refer to seasonal movement of people of the Arctic region, has implications of a lack of agency in this movement, which was previously considered to hinder "development" of the North [12]. As my work explores the process of dispersal, not dispersal as a contentious and politically denigrating term, I endeavored to avoid unwanted political undertones by focusing on the present: How did the residents of and visitors to the Arctic, whom I was interviewing, relate to climate change? How did their own travels or migration or those of their families affect their sense of identity and culture? How did digital tools affect this?

\section{Water | Ice and Sea}

For The Matter of the Soul, I chose to explore the ice/ocean/ water perspective using scientific equipment that measures water acidity and salinity. A fundament of The Matter of the Soul, and my artistic practice, is the exploration of multiple knowledges and their relation to agency and action. My work challenges established knowledge hierarchies by juxtaposing two positions: the act of measurement as a proxy for action, and tacit and embodied knowledge as a necessary component of our understanding of the other(s) [13].

I subverted the process of measurement in The Matter of the Soul by modifying scientific instruments to generate sound, repurposing their measurements into a sound-based artwork focusing on uncodifiable emotional response. I obtained and hacked scientific equipment that is usually used to measure the $\mathrm{pH}$ and salinity of liquids: a Mettler Toledo Delta $320 \mathrm{pH}$ meter and a Jenway 4010 Conductivity Meter. I hacked the equipment, which are designed to provide numerical data, using circuit bending: taking apart electronics and probing the circuit using resistors to discover through which point of the circuit voltages flow that give rise to sounds (Fig. 2) [14]. In this way it is possible to make audible and record the sounds generated by the changes in voltage in the equipment while they measure these physical properties of water [15].

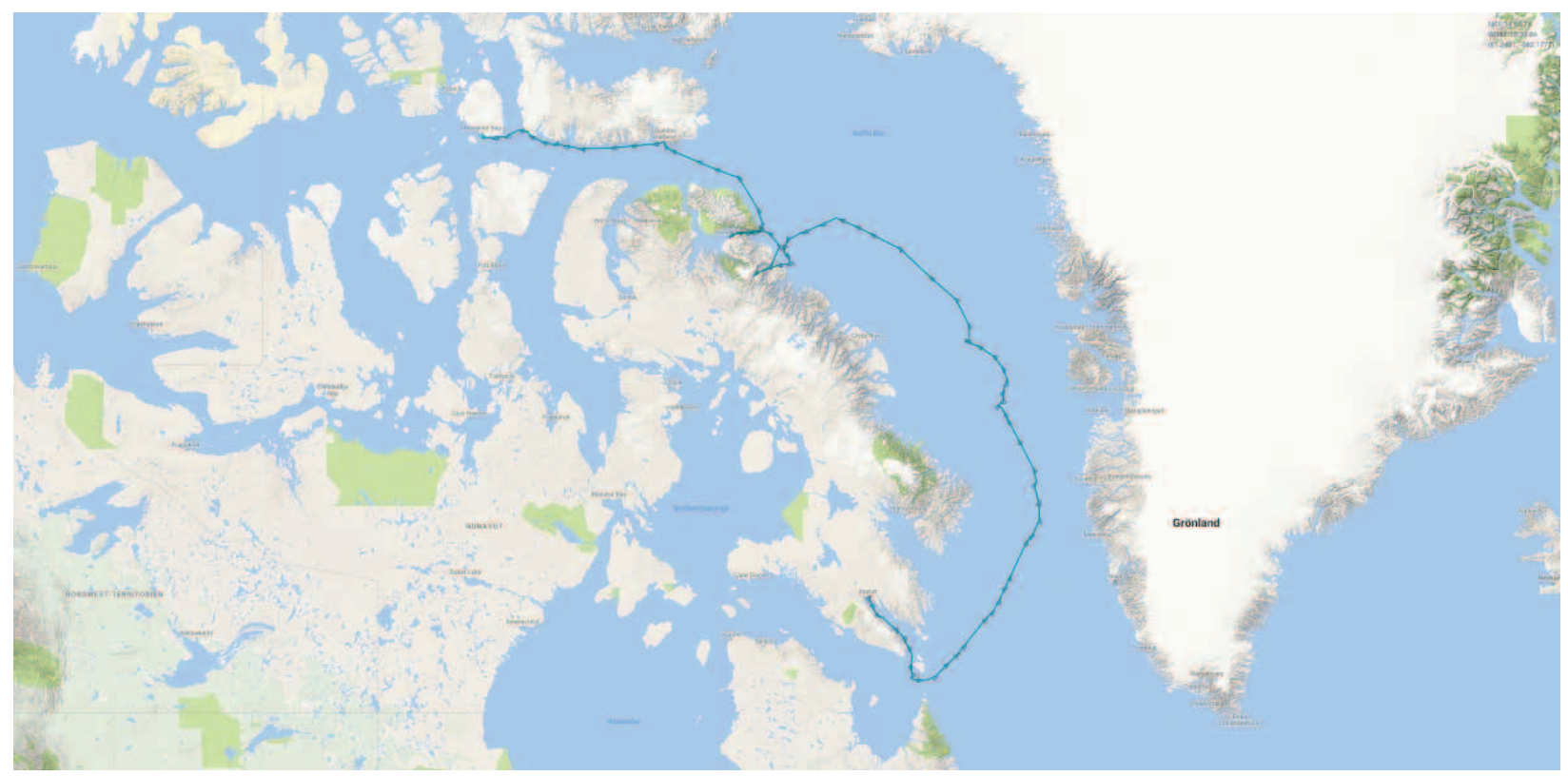

Fig. 1. The route from lqaluit, Baffin Island, to Resolute, Cornwallis Island. (Image: Peter Lindner) 


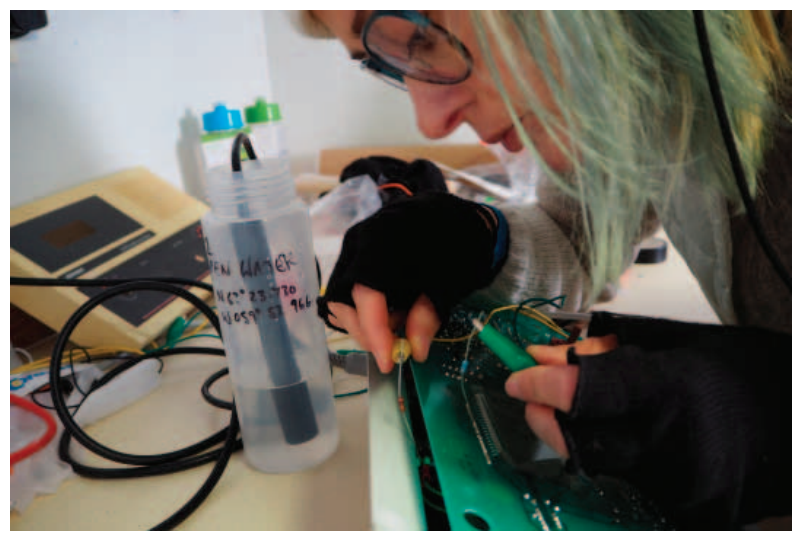

Fig. 2. Hacking the conductivity meter aboard ship. (๑) Kat Austen)

Sound from the $\mathrm{pH}$ meter was taken from pins on the digital display and captures the jumps in measurement shown on the display as the $\mathrm{pH}$ meter equilibrates around a final value. This method of capturing the act of measurement-offset, abstracted, nonrepresentational-intentionally shines a light on the process of measurement itself and its place in our action with respect to climate change.

The conductivity meter varies its sonic output temporally - a sound similar to feedback pulses in volume as the measured value of conductivity wanes after a measurement is made. The conductivity meter thus speaks not of what it measures but of the absence of measurement. This delicate change in volume as the signal dies is a moving analogue for the incremental sigh of the dispersing Arctic ice.

The sounds generated from both machines are not directly representative of the value of the measurements; it is not sonification of data but rather a reflection on the process of measurement as a way of knowing. The sounds, in capturing the dynamism of the measurement process, reflect also the ephemerality and dynamism of an ever-evolving ecosystem balancing forces in flux. Thus, they speak more for the evolution of ecosystems through time than would the capturing of a single value, a snapshot of an instant in a time past.

I used the hacked instruments alongside microphones and DIY hydrophones to make field recordings of the Arctic waters during the trip (Fig. 3). I also collected water samples, recording the location and GPS coordinates each time, for use in later performances. I took samples of water from different points in the process of dispersal: freshwater runoff from glaciers on land, land-based lakes, ice from icebergs, bay water, water directly at the ocean coast and open sea water.

\section{COMPOSITION AND CREATION}

The Matter of the Soul comprises a sono-sculptural and new media installation, digital and cassette release, and live performance. Each of these outputs centers upon a musical composition, The Matter of the Soul | Symphony, written in four movements and composed along the conceptual principles of dispersal between two metastructures. The work elaborates this concept through the three examples of individuals | metastructures detailed above. The symphony combines

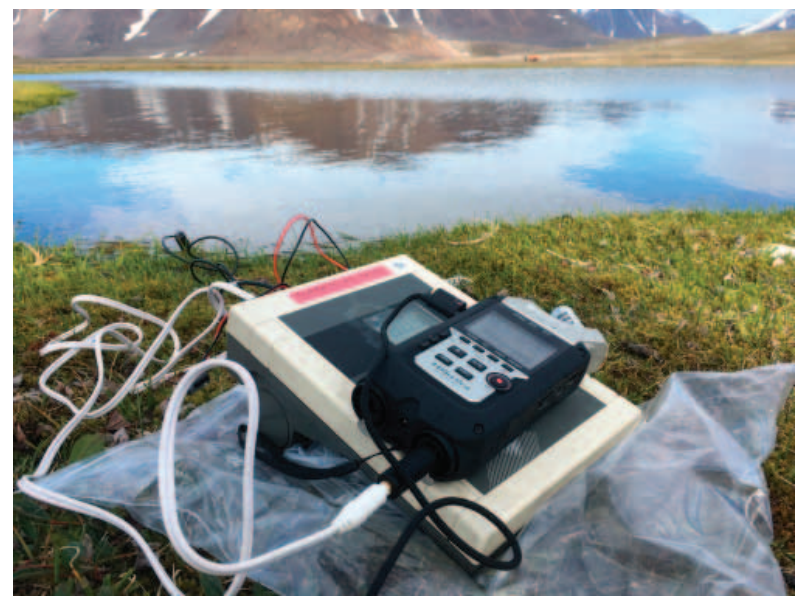

Fig. 3. Field recording using hacked $\mathrm{pH}$ meter on Devon Island. (@ Kat Austen)

the field recordings described above with piano, percussion and synthesizers. This experimental electronic music composition both elaborates upon and challenges the symphonic form. Further discussion of the choice of interview excerpts is provided in supplementary materials; the transcript is published elsewhere [16]. Audio samples and example field recordings are available on GitHub [17], and the composition can be listened to on Bandcamp [18].

The first movement, biphasic, works with the form of a sonata; stating, developing and recapitulating its narrative. The movement evokes two metastructures that coexist in space but do not interact; it is a loneliness, a coexistence physically but not emotionally. In composing biphasic, I selected samples from interviews that reflected a distance between cultures that encounter one another: samples that emphasize "otherness." These are combined with sound recordings of the Arctic's separate water structures of freshwater runoff and deep open water.

The rhythms and melodic progression in biphasic evoke a sense of the uncanny. They first establish musical rules, matching rhythms between samples and working, in the piano sample, with melodic progressions, only to insert unexpected, subtle disruption through marginally extended beats and occasional dissonant notes. This creates disruption and discomfort that is amplified by the use of the conductivity meter samples, which also disrupt the rhythm and introduce a subtle urgency with their fuzzy, high pitch, and the dissonant, square wave varying pitch from the $\mathrm{pH}$ meter. I use stereo channels in biphasic to offset different voices and locations against one another in the sound design, to emphasize the "otherness" in the composition.

In the second movement, concentration, we experience the effects of partial mixing. When the water from the glaciers and icebergs first encounters open water, a layering occurs, where weaker, less saline water sits on top of sea water. Similarly, when a person first interacts with another culture, the input is assessed consciously, but it has not yet affected behavior. There is some "taking in" of the otherness but not assimilation.

In concentration the tempo is slower and more open. The composition is built around percussion and the field record- 
ings. The partial mixing is reflected by the choice of audio recordings of water taken from points of mixing-bays and inlets-and in the choice of phrases taken from interviews that show an awareness of other cultures but no change in identity of the individual or culture: "My mother is living in Down South now." I use DIY hydrophone recordings to introduce the fluidity of water and mixing alongside excerpts where the metaphor is emphasized: "The metaphor of water flowing and mixing and being free." These convey the message that the water has no vested interest in being frozen.

dissipation, the third movement, fits with the standard scherzo characteristics of being faster paced and including certain humorous elements. Temporally, dissipation addresses the contemporary Arctic in terms of climate change and cultural changes. It deals with the creation of something new from the assimilation of the individual(s) into another metastructure. Synthesizer sounds create a challenge with a certain irreverence while simultaneously establishing a lulling rhythm at the start of the movement.

Finally, in the fourth movement, multiphasic, I evoke the rondeau form by focusing on vocal expression and repetition. The movement begins with a conversation excerpt between me and a retired professional skier. "How do you feel about snow?" I ask. She repeats my question with emphasis: "How do I feel about snow?" she chuckles. We progress through the rondeau, which recalls the voices and themes from the previous movements and over which I introduce the only sung vocals of the piece. These come to an abrupt end when we hear the skier again repeat the question. She then pauses and ends the symphony with her answer: "I love snow."

\section{DISPERSAL OF DISPERSAL}

I released The Matter of the Soul|Symphony as a digital download and on audio cassette [19]. This physical format was chosen for its technical ease of physical remixing while allowing preservation of the audio quality. In addition, raw audio has been released online [20] and has subsequently been used by composer John Morrison in The Realities We Play [21] and by video artist Jemma Woolmore [22].

The Matter of the Soul installation comprises a light box, an acrylic sculptural sound installation (playing the symphony), video and relief canvases. One cassette has been "frozen" in an acrylic sculpture, a time capsule of this tipping point in our choices of climate action. The work has a central motif (see Fig. 4) that resonates with the aesthetic of dispersal in the Arctic geomorphology. The form is a combination of passive surrender to the external force of gravity combined with an active downward force, as seen in the gullies cut by glacial meltwater rushing downward toward Arctic bays. The predominant color of all the visual elements is red: the shock of blood on ethereal ice: biological life and death in a seascape out of time. Red is an important color in Inuit culture, where words relating to things red in color are frequently derived from the Inuit dialect word for blood, aðuy [23]. The installation also makes use of the audio cassettes that form part of the musical release.

I have performed The Matter of the Soul around the globe,

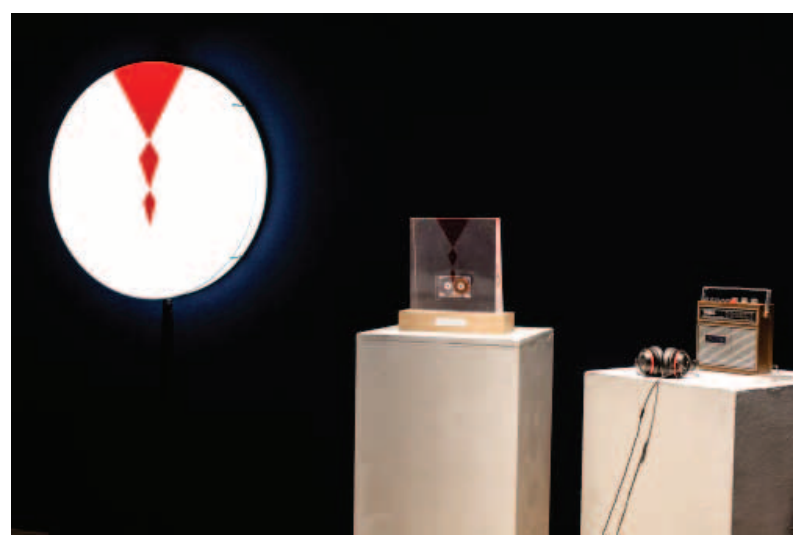

Fig. 4. The Matter of the Soul, acrylic light box, acrylic, wood and cassette, cassette player and headphones, 2018, at Bonhams Art Gallery. (๑) Kat Austen. Photo (C) nkproductions.org, 2018.)

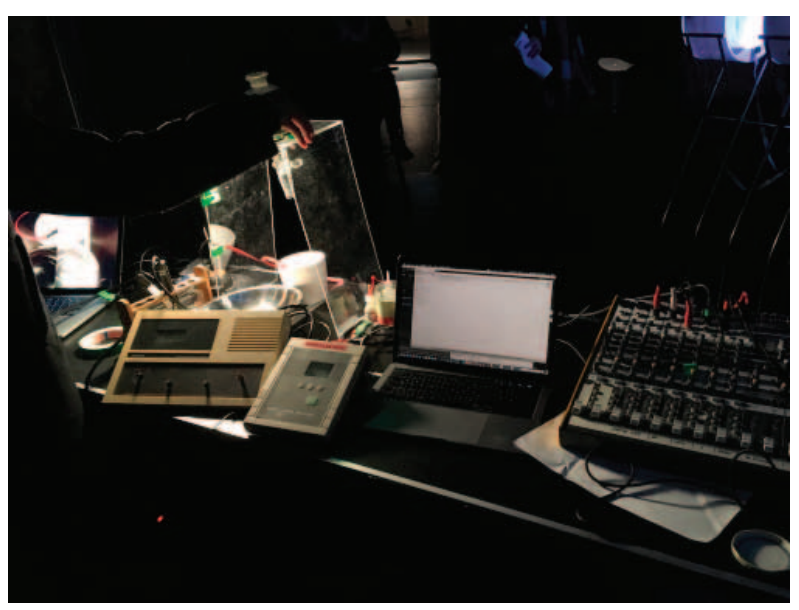

Fig. 5. Performance setup with hacked instruments. (C Kat Austen)

including as part of a climate change-focused residency at Headlands Center for the Arts, U.S.A., as well as at MusicTechFest Stockholm. During the performance, I "play" samples of Arctic water using the hacked instruments (Fig. 5), altering the water's physical properties to produce changes in sound in the instruments, in improvisation with the symphony composition. For each performance I have altered the work, sometimes by introducing local water samples or by inviting different collaborators. I collaborated with musicians Matthew Bourne and Alex Bonney at Howard Assembly Rooms, Opera North, Leeds [24], and with choreographer Kasia Witek at ClimateHub by Greenpeace at $\mathrm{COP}_{24}$, Katowice, Poland (Fig. 6). At klasica, a sustainability-themed symposium in Taipei, Taiwan, I reinvented The Matter of the Soul by combining it with a cocreation workshop, where I worked with participants to create a new song, Cries of Climate Change. These reimaginings of the work are concurrent with the digital dispersal of the work and achieve the same end: The identity of The Matter of the Soul is intertwined with its context-both affecting and being affected by each performance, embracing the dynamism of the process of dispersal. 


\section{CONCLUSION}

Dispersal for humans is emotionally loaded. In terms of physical changes to water, dispersal is a value-neutral transformation. Yet when viewed in the context of climate change, from our knowledge of the magnitude and irrevocability of this transformation, it also incorporates a deep sense of loss. Dispersal forces us to question our attitudes to human movement of tourism and migration as socioeconomic factors, as causes for cultural change and as contributors to climate change.

The research behind The Matter of the Soul took various forms; it employed scientific knowledge, hacked scientific equipment, ethnographic and journalistic research and aesthetic research. Crucial to the work's development, however, was the lived experience of being in and being with the Arctic at a time of melting. Searching for this ephemeral feeling of dispersal with/in this fragile entity is a unique, transformative and indispensable experience that is now woven into The

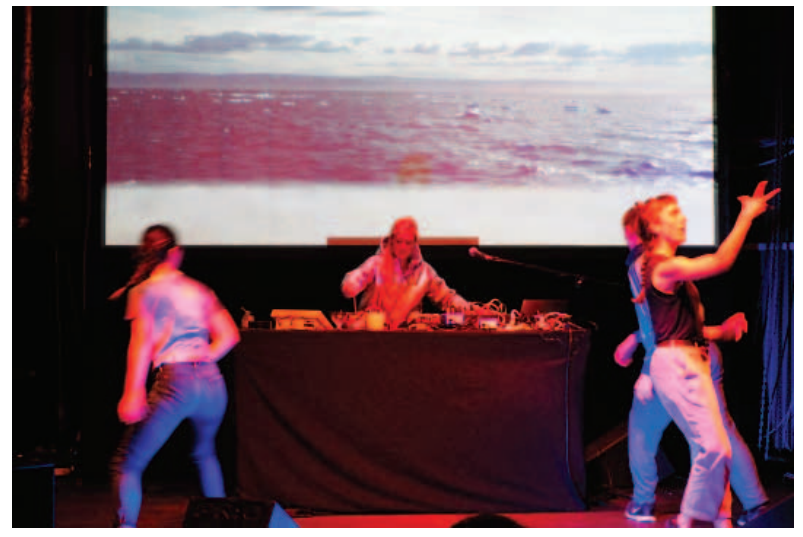

Fig. 6. Performing with Kasia Witek and dancers at ClimateHub, Katowice. (Photo () F. Glowinski)

Matter of the Soul. As such, the sadness for Arctic melting and migration that is conveyed in the composition is a very human sadness about the consequences of climate change for our current way of life.

\section{Acknowledgments}

My thanks go to Crosby Medley, who runs the UCL Chemistry Graham Laboratory, for donating the chemical instruments; the Cultural Institute, University of Leeds, for my Cultural Fellowship, which supported the production of this work; and Simon Schäfer, who introduced me to circuit bending.

\section{References and Notes}

1 Oxford Dictionaries, dispersal: https://en.oxforddictionaries.com/ definition/dispersal (accessed 23 December 2018).

2 K. Austen, "Mediating for Climate Change: Falling Up to Hyperignorance, Diving Down to Deep Waters, to Touch Other(s) (and Ourselves)," OAR: The Oxford Artistic and Practice Based Research Platform 2 (2017) pp. 69-78.

3 Austen [2].

4 M.K. Sejr et al., "Evidence of Local and Regional Freshening of Northeast Greenland Coastal Waters," Scientific Reports 7 (2017) pp. 2-6.

5 Joseph Cheek, "Explaining Ocean Acidification and Consequences for Arctic Marine Ecosystems," SciencePoles (31 March 2014): www .sciencepoles.org/interview/explaining-ocean-acidification-and-con sequences-for-arctic-marine-ecosystem (accessed 23 December 2018).

6 A. Rapp, "Slope Processes in High Latitude Mountains," Progress in Physical Geography: Earth and Environment 10, No. 1, 53-68 (1986).

7 A. Castleton, “Technology and Inuit Identity: Facebook Use by Inuit Youth," AlterNative 14, No. 3, 228-236 (2018).

8 H. Williams et al., "Network Analysis Reveals Open Forums and Echo Chambers in Social Media Discussions of Climate Change," Global Environmental Change 32 (2015) pp. 126-138.

9 J. Aslan et al., "Electricity Intensity of Internet Data Transmission: Untangling the Estimates," Journal of Industrial Ecology 22, No. 4, 785-798 (2017).

10 www.spri.cam.ac.uk/friends/artistinresidence/artists/austen.

11 Pan-Inuit Trails Atlas: www.paninuittrails.org (accessed 23 December 2018).

12 E. Anderson and S. Bonesteel, "A Brief History of Federal Inuit Policy Development: Lessons in Consultation and Cultural Competence," Aboriginal Policy Research Consortium Interna-

tional (APRCi) 70 (2010): https://ir.lib.uwo.ca/cgi/viewcontent .cgi? article $=1374 \&$ context $=$ aprci.

13 K. Austen, "Multiple Knowledges and the Redefinition of the Self in the Environment," Artistic Research Will Eat Itself: Proceedings of the 9th SAR International Conference on Artistic Research (University of Plymouth, 2018) pp. 1-15.

14 Qubais Reed Ghazala, "The Folk Music of Chance Electronics: Circuit-Bending the Modern Coconut," Leonardo Music Journal 14 (2004) pp. 97-104.

15 K. Austen, "How I Made Musical Instruments from Lab Equipment to Create Empathy with the Arctic," The Conversation (31 October 2018): www.theconversation.com/how-i-made-musical -instruments-from-lab-equipment-to-create-empathy-with-the -arctic-105685 (accessed 2 January 2019).

16 K. Austen, "This Fractionation of Our Being," Soundest 3 (2019).

17 Available at www.github.com/iamkat/the_matter_of_the_soul (accessed 2 January 2019).

18 Available at www.katausten.bandcamp.com/album/the-matter-of -the-soul-symphony (accessed 2 January 2019).

19 See Ref. [17].

20 Austen [16].

21 Available at www.soundcloud.com/fifth-morrison/the-realities-we -play (accessed 2 January 2019).

22 Jem the Misfit and Al-i-ce, All that is left, at Spektrum, Berlin, 2019.

23 M. Fortescue, "The Colours of the Arctic," Amerindia 38 (2016) pp. 25-46.

24 Production additionally supported by IceAlive.

Manuscript received 2 January 2019.

KAT AUSTEN is a person. She creates artworks that explore the boundary between the self and other, with a particular focus on the impact on our relationship to environmental change. She is based in Berlin and is a teaching fellow at UCL Arts and Sciences BASc. 